\title{
Analysis and Application of Hydropower Real-time Performance Calculation
}

\author{
Dequn Feng ${ }^{1}$, Zhiwei Wang ${ }^{2}$, Pengbo $\mathrm{Ma}^{2}$, Wenqing Wang ${ }^{2}$ \\ ${ }^{1}$ Xi' an Electric Power College, Xi' an, China \\ ${ }^{2} \mathrm{Xi}$ 'an Thermal Power Research Institute, Xi'an, China \\ Email: fdqqwmm@126.com
}

Received March, 2013

\begin{abstract}
The hydropower running and performance can be displayed and analyzed by the real-time remote system. Real-time performance data of the hydraulic turbine unit can be obtained through the analysis of real-time operating data of the hydraulic turbine unit. It can not only guide significance for long-term operation of hydraulic turbine unit, but also provide a reference for improving the Hydropower hydro efficiency, economic dispatch of hydraulic turbine unit and performance comparison before and after the overhaul.
\end{abstract}

Keywords: Hydropower Units; Performance Analysis; Efficiency

\section{Introduction}

Same type of hydraulic turbines could have different turbine efficiency due to different design and manufacturing level or defects caused during production or installation process. It is quite important to manage to make full use of water resources and improve the ec nomic performance of hydropower station by understanding the actual running efficiency of hydraulic turbines and avoiding turbine operation at low efficiency areas.

\section{Power Plants Production Real-time Monitoring System}

A power plant or power generation group production real time monitoring system (hereinafter referred to as the system) the realization of the data acquisition, real-time transmission site, centralized storage and hydroelectric station of on-line performance calculation and analysis For power plants or electricity power generation groups, the production real-time monitoring system (hereafter referred as System) realizes the on-site data collection and real-time transmission, as well as the centralized data storage and online performance calculation and analysis of hydropower stations[1].

To ensure the accuracy and reliability of the real-time performance calculation, raw data to be collected from the control system in hydropower stations directly. Based on IEC60870-5-101 or IEC60870-5-104 standard protocol, instant data is collected from the designated measuring points of the control system[2].
Data collection needs to consider the following: must ensure that data is collected in time accuracy of seconds; data to be buffered and stored locally in case of lack of transmission bandwidth or interruption caused by any abnormal condition, and the data must be loaded back automatically upon network link restoration.

\section{Calculation of the Performance of Hydropower Stations}

Lots of problems could incur to apply the performance data of the model machine on a prototype, as the operation characteristic curve of the hydraulic turbines is calculated based on the experimental model machine, where the prototype differs from the model machine in many ways, such as installation precision, the scale effect between the two, quality differences of the turbines (especially rotations) from manufacturing and so on. The turbine performance calculation in accordance with the "GB/T 20043-2005 Field acceptance is tested to determine the hydraulic performance of hydraulic turbine, storage pumps and pump-turbine"[3].

Normally the long-term and instant performance monitoring is unable to be achieved as the turbine operation efficiency test is typically carried out after performance defects appear or upon overhaul.

Under the guidance of "DL/T 262-2012 thermal power unit coal consumption online guide to the calculation of" and in accordance with GB/T 20043-2005 standard, realtime calculation of the performance of hydropower stations can be achieved[4]. The performance of hydraulic turbines is calculated online: first calculate out the main 
economic index of the hydropower station based on real-time running data, and then, by applying the historical data, the curve of the economic indicators of the hydraulic turbines are produced. The numbers and installation positions of measuring points required to calculate the performance are determined based on the analysis of the site condition. The System accomplishes the online performance calculation of hydraulic turbines, and the analysis results can be used as the basis of judgment and decision making over the real-time economic situation for power plants.

\subsection{Hydraulic Turbines' Stage Efficiency of Calculation Principle}

Hydraulic turbines' stage efficiency is the ratio between turbine shaft power and water power. Considering the difficulty in measuring the turbine shaft power, the efficiency of the hydraulic turbine units can be calculated out by applying the same method as that in the prototype efficiency experiment, and then the efficiency of hydraulic turbines can be produced by converting and calculating the characteristic efficiency curve of the turbine power generator.

Hydraulic turbine unit efficiency is defined as follows

$$
\eta_{\mathrm{slju}}=\frac{N_{e}}{N_{T O}}=100 \times \frac{\mathrm{N}_{\mathrm{e}} \times 10^{6}}{\mathrm{Q}_{\mathrm{slj}} \rho \mathrm{gH}_{\mathrm{st}}}
$$

Hydraulic turbine efficiency is described as

$$
\eta_{\text {slj }}=100 \times \frac{N_{e} \times 10^{6}}{Q_{s l j} \rho g H_{s t}}=\eta_{s l j} / \eta_{f d j}
$$

Hydraulic Turbine power generation water consumption is defined as

$$
b_{\mathrm{sljt}}=\frac{3.6 \times \rho \mathrm{Q}_{\mathrm{slj}}}{\mathrm{N}_{\mathrm{e}}}
$$

where:

$\mathrm{Ne}$-A generator output power, $\mathrm{MW}$;

$\mathrm{N}_{\mathrm{TO}}$-Hydraulic turbines' input power, $\mathrm{MW}$;

$\mathrm{n}_{\mathrm{g}}$ - Generator efficiency, $\%$;

$\eta_{\text {slju }}$ - The efficiency of the Hydraulic turbine units, \%;

$\eta_{\mathrm{slj}}$-hydraulic turbine efficiency, $\%$;

$\mathrm{b}_{\mathrm{sljt}}$-hydraulic Turbine power generation water consumption, $\mathrm{kg} /(\mathrm{Kwh})$

$\mathrm{Ne}$-Power generation active power, MW;

$\mathrm{Q}_{\mathrm{slj}}$-Hydraulic Turbine water flow, m3/s;

$\rho$-Over the water density, $\mathrm{kg} / \mathrm{m} 3$;

g-Acceleration of gravity, 9.8066, m/s2;

$\mathrm{H}_{\mathrm{st}}$-Working head, $\mathrm{m}$

\subsection{Data Processing}

Based on the actual situation of hydropower stations, parameters to be collected for on-line calculation include: output power of the power generator, water flow rate passing through, working head of the turbine and so on; Parameters that are not able to be collected on-line such as the acceleration of gravity, water density, the efficiency of the power generator etc. can be applied based on pre-defined value from design, and can then be determined by evaluating their effects according to formula (1) $\sim$ (3) and processed at final stage where the calculation result is corrected eventually.

It is recommended that the real-time data be taken at the last 2 minutes average value (taking into account of any data mismatch and/or fluctuations) and the data real-time rationality verification be adopted, so as to avoid input the calculation module any abnormal data caused by poor communication or bad data collection. The actual data verification methods vary by the characteristics of parameters. Whenever a key data is replaced, data is to be screened and filtered to avoid any potential impact on the result. The way of data screening and filtering should be carried according to the actual calculation method, effect of parameters, background professional knowledge etc. The calculation to be done against the actual situation, avoiding un-representative results due to poor data stability caused by low workload, start and stop operation and so on.

\subsection{On-line Calculation Software}

On-line calculation should adopt the approach making use of modular software tools capable of on-line calculations. This software tools is required to be able to configure the reasonable calculation frequency flexibly, with easy and quick ways of achieving calculation method, capable of measuring the irrational cases inside the mathematical logic, diversified logical determination and rich mathematical processing function, reversing back calculations where necessary, stable and reliable running, and with the ability to control strictly the data reading time and time sequence during calculation.

\section{Engineering Applications}

The System operates at one hydropower station in Xinjiang: the power station was designed to adopt runoff type turbines that intake water. Having the fall of $218.5 \mathrm{~m}$, it was developed in 2 stages. The biggest water head of the turbine in the first stage is $105.8 \mathrm{~m}$ by design and rated at $100.8 \mathrm{~m}$, while the smallest water head was designed as $100.7 \mathrm{~m}$, with rated flow at $34.65 \mathrm{~m}^{3} / \mathrm{s}$; the biggest water head in the second stage was designed as $102.2 \mathrm{~m}$, rated at $100.8 \mathrm{~m}$, and the smallest one is $100.7 \mathrm{~m}$.

Production real-time monitoring system realizes instant data remote acquisition and online calculation of the hydropower main index[5]. The running and economic situation of the unit can be monitored by operation 
and management staff at real time[6].

\subsection{Real-time Performance Display}

With regard to the physical layout of the hydropower station, the System processes key parameters and displays on screen the running status in real time. Display is rendered based on the actual situation on site, in the way varies by specific interested parameters, as shown in Figures 1-4.

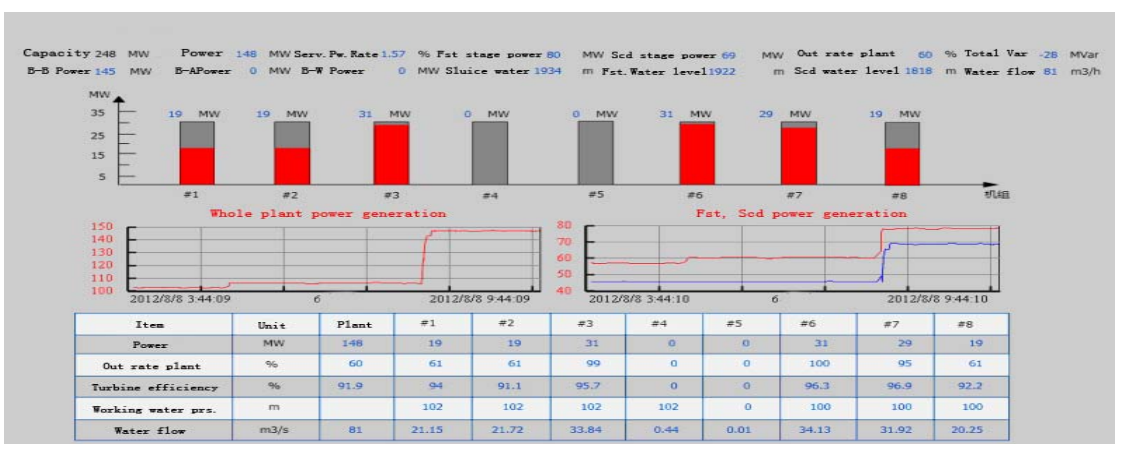

Figure 1. Hydropower run-time performance of the screen.

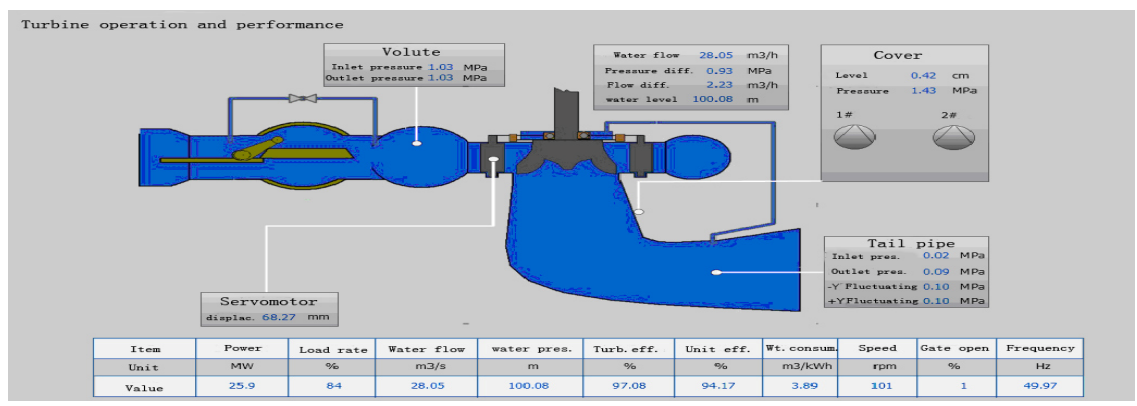

Figure 2. Hydropower run-time system.

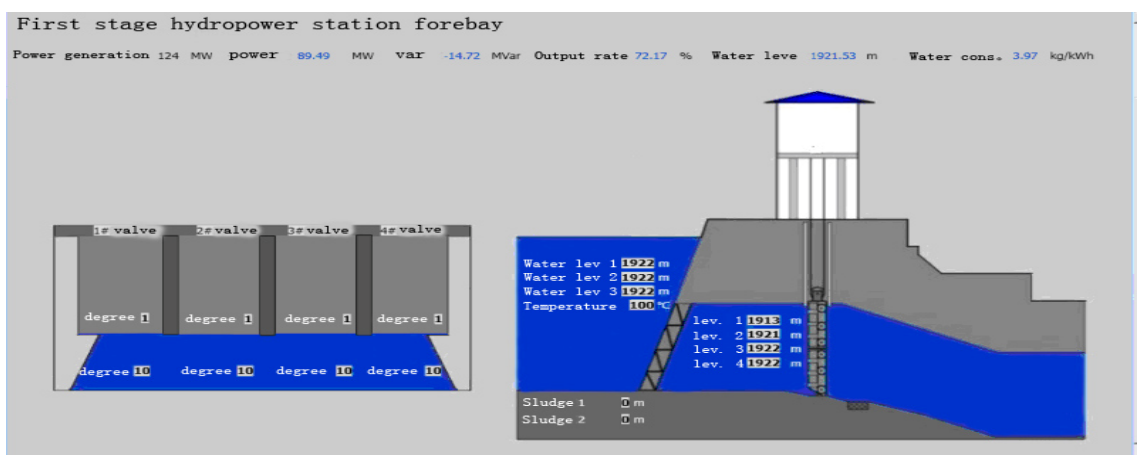

Figure 3. The a station forebay run screen.

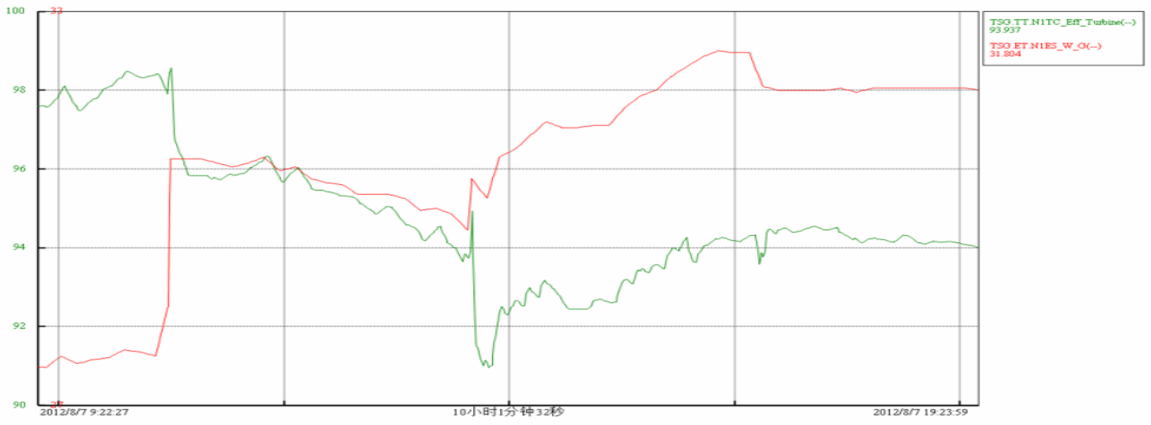

Figure 4. Power generation load and hydroelectric generating efficiency curve. 


\subsection{Unit Performance Comparison}

The System calculates performance data of the hydraulic power station such as the efficiency of hydraulic turbines, turbine units, water consumption for power generation etc. The efficiency and relevant parameters of the turbine units in the second stage is analyzed for the workload between 30 31MW and $27 \mathrm{MW}$.

Analyzing the historical data, it indicates there's no much difference on the performance of hydraulic turbines within certain time range; analysis is done on data in a period of the latest two months and the result are shown in below Tables $\mathbf{1}$ and $\mathbf{2}$.

As the load increases, the motor efficiency is improved; the motor efficiency could be adjusted on low loads; if motor efficiency is $97.5 \%$, the turbine efficiencies after adjustment are: $96.04 \%, 95.76 \%, 93.47 \%, 95.88 \%$ respectively.

Referring to the performance curve of turbines in hydropower station (Figure 5), it's clear that the online calculations of hydraulic turbine efficiency is in accordance with the basic trend of the design curve, with the best efficiency when turbines working at 27 29 MW.

Table 1. $30 \mathrm{MW}$ performance comparison.

\begin{tabular}{|c|c|c|c|c|c|}
\hline Item & Unit & 1 & 2 & 3 & 4 \\
\hline Power generation & MW & 30.70 & 30.71 & 30.77 & 30.60 \\
\hline The water level & $\mathrm{m}$ & 1818.2 & 1818.0 & 1818.2 & 1818.4 \\
\hline Over the water flow & $\mathrm{m} 3 / \mathrm{s}$ & 33.81 & 33.70 & 33.57 & 34.03 \\
\hline $\begin{array}{l}\text { Working water } \\
\text { pressure }\end{array}$ & $\mathrm{m}$ & 100.15 & 100.15 & 100.15 & 100.15 \\
\hline $\begin{array}{l}\text { Water consumption for } \\
\text { power generation }\end{array}$ & $\mathrm{m} 3 / \mathrm{kwh}$ & 3.96 & 3.94 & 3.93 & 3.98 \\
\hline $\begin{array}{l}\text { hydraulic turbine } \\
\text { efficiency }\end{array}$ & $\%$ & 95.45 & 95.84 & 96.37 & 93.34 \\
\hline $\begin{array}{l}\text { Servomotor } \\
\text { displacement }\end{array}$ & $\mathrm{mm}$ & 82.67 & 80.25 & 79.63 & 84.92 \\
\hline
\end{tabular}

Table 2. 27 MW performance comparison.

\begin{tabular}{lccccc}
\hline \multicolumn{1}{c}{ Item } & Unit & $\mathbf{1}$ & $\mathbf{2}$ & $\mathbf{3}$ & $\mathbf{4}$ \\
\hline $\begin{array}{l}\text { Power generation } \\
\text { The water level }\end{array}$ & $\mathrm{MW}$ & 26.94 & 27.35 & 27.76 & 27.25 \\
$\begin{array}{l}\text { Over the water flow } \\
\begin{array}{l}\text { Working water } \\
\text { pressure }\end{array}\end{array}$ & $\mathrm{m} 3 / \mathrm{s}$ & 29.03 & 29.56 & 29.65 & 29.41 \\
$\begin{array}{l}\text { Water consumption for } \\
\text { power generation }\end{array}$ & $\mathrm{m} 3 / \mathrm{kwh}$ & 101.5 & 101.5 & 101.5 & 101.5 \\
$\begin{array}{l}\text { hydraulic turbine } \\
\text { efficiency }\end{array}$ & $\%$ & 97.52 & 97.23 & 3.98 & 3.89 \\
$\begin{array}{l}\text { Servomotor } \\
\text { displacement }\end{array}$ & $\mathrm{mm}$ & 71.78 & 70.88 & 71.70 & 73.56 \\
\hline
\end{tabular}

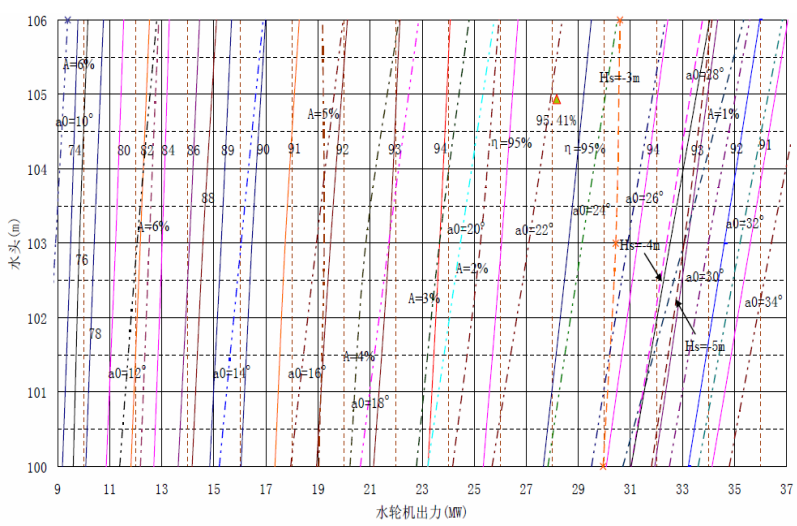

Figure 5. Hydropower run-time performance of the screen.

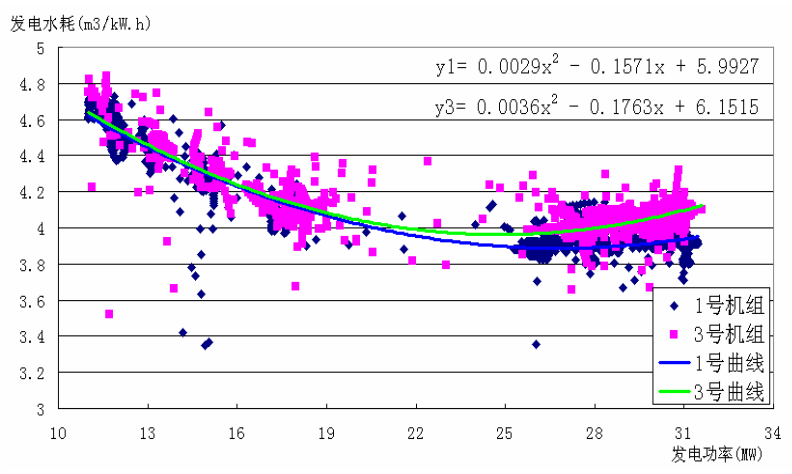

Figure 6. Hydropower run-time performance of the screen.

The water density is considered as constant value taking into account that full workload time of the turbine units are very close. The working water heads take the same value as well, referring to Tables $\mathbf{1}$ and $\mathbf{2}$, the water levels of the front pool remain around $1818 \mathrm{~m}$ with no much difference, and all the turbine intake centre lines are around $1708 \mathrm{~m}$. By evaluating one month capacity and water consumption figure of the power generation in various workloads of the No.1 and No.3 units, taking about 8000 sets of data each measuring point, comparison chart of the capacity and water consumption of the power generation in various workloads of the No.1 and No. 3 units is produced in figure 6 .

Figure 6 shows that No. 1 and No. 3 unit have similar water consumption for power generation under $20 \mathrm{MW}$ load; both water consumption increases round $27 \mathrm{MW}$ load, and Unit No. 1 has a minimum consumption around 25.08 MW load while Unit No.3 has minimum consumption around 27.09 MW. Comprehensive analysis indicates that Unit No.1 should be put into operation when load is low, while for heavy loads; the turbine efficiency of Unit No. 3 is $1 \%$ higher than that of Unit No.1 even the water consumption of Unit No.3 is higher.

In same way of comparison and analysis, relevant characteristics such as relations appearing in curves between the power of hydraulic turbine and opening degree 
of the guide vane valve within a unit can be produced.

\section{Conclusions}

Remote data collection of hydropower stations achieves instant data analysis and display; resolve the online efficiency calculation of the power of the hydraulic turbine prototype.

Through long-term operation practice, coupled with the correct and reasonable approaches on data analysis, the performance changes of turbines can be analyzed; not only it provide the basis for the operation and management staff to understand the performance of turbines and make decisions, also it has significant guidance to schedule optimization for power stations.

\section{REFERENCES}

[1] Z. W. Wang, D. Yang and H. H. Hu, "Company-level Plant Operational Information Systems Research and
Development, 2006 High-Level Forum of the Power of Information Technology, Yangzhou, 2006, pp. 193-194.

[2] X. Ge, D. Yang and Y. Wang, "Study on an Development of Real-time /Historic Database System Oriented to Power Industry," Thermal Power Generation, 2010, Vol. 39, No. 04, pp. 91-94.

[3] GB/T 20043-2005, "Field Acceptance Test to Determine the Hydraulic Performance of Hydraulic Turbine," Storage Pumps and Pump-turbine.

[4] DL/T 262-2012, “Thermal Power Unit Coal Vonsumption Online Guide,”.

[5] Z. W. Wang and P. B. Ma, "Real-time Monitoring Technology Development Report of Huaneng Xinjiang Energy Development Co. td., 2012.

[6] D. Q. Feng, T. Li and H. Wang, "Application of Monitoring and Control Software in Makeup Water Treatment System of Thermal Power Plant," Electric Power Automation Equipment, Vol. 27, No. 6, 2007, pp. 111-113. 